\title{
Effects of Addition of Sprint, Strength and Agility Training On Cardiovascular System in Young Male Field Hockey Players: An Echocardiography Based Study
}

\author{
Barun Hanjabam ${ }^{1}$, Jyotsna Kailashiya ${ }^{2 *}$ \\ ${ }^{I}$ Department of Sports - Exercise Medicine and Sciences, \\ North-East Regional Centre, Sports Authority of India, Imphal, Manipur, India. \\ ${ }^{2}$ Department of Biochemistry, Institute of Medical Sciences, \\ Banaras Hindu University, Varanasi, Uttar Pradesh, India.
}

\begin{abstract}
To find training related physiological and cardiovascular changes and adaptations in field hockey players, this interventional study was conducted with 30 male field hockey trainees (age: 15.7 \pm 1.55 years, range: 13-20 years) undergoing training in preparation phase. In addition to the their usual routine of 2 hours per day, 6 times a week of aerobic, anaerobic and skill training session of field hockey; a specialized additional training of 2 hours per day- 3 times a week, consisting of sprint, strength-power and agility was incorporated in the schedule. Selected variables measured before and after the 6 week training were compared with paired $t$ test. Upon analysis we found that lean body mass (LBM) of the participants showed significant improvement $(P<0.05)$ after the 6 week training. Significant reduction $(P<0.05)$ was observed in resting heart rate, resting systolic blood pressure, resting diastolic blood pressure, resting double product or rate pressure product. We also found significant changes $(P<0.05)$ in the echocardiographic parameters - increase in left ventricular posterior wall thickness, left ventricular ejection fraction; and decrease in left ventricular end-systolic volume. However when these parameters were expressed relative to LBM, no significant change was seen. Left ventricular end-diastolic diameter and volume, body weight and body mass index too did not change significantly after the training. This 6 week specialized additional training resulted in improvement of body composition and cardiovascular functions of the participants, indicating favorable physiological, morphological and functional adaptations.
\end{abstract}

Key words: field hockey; physiological adaptations; sports physiology; body composition; echocardiography; lean body mass.

\section{Introduction}

Field hockey is one of the very popular sports of the world which demands high strength, anaerobic power and agility of the players in addition to the usual requirement of good skill and aerobic fitness. As for other sports, physique and body composition has a very significant influence over the game of hockey. This sport involves mainly intermittent high intensity pattern of activity, demanding high aerobic and anaerobic fitness [1-3]. Frequent short sprints, change of directions and accelerations-decelerations are very common in addition to walking and jogging to cover large area of the ground. Hence sprint, strength and agility exercises are very essential part of field hockey training along with endurance and skills training.

The training results in various physiological adaptations in the player's body. Cardiovascular system of the trainee is largely involved in such adaptations. Decrease in resting heart rate, blood pressure and the double product or rate pressure product as results of exercise has been reported earlier [4-6]. The heart itself may undergo adaptive morphological and functional changes as a result of changes in hemodynamic. These adaptations may occur within weeks or months after starting of strenuous training and may be reversed following its cessation [7]. The dimensions of the changed structures rarely exceed upper limits of those of normal and significantly lower than those seen in pathological conditions [8]. These positive adaptations not only help to meet the imposed physiological demands, but also in improving general health status of the trainees. Echocardiography is a very useful technique to assess morphological and functional status of the heart.

\section{Methods}

In order to find the training related changes and adaptations, we designed this study based on echocardiographic, anthropometric and physiological assessment before and after 6 weeks of additional specialized training in 30 young male hockey players and compared the measured variables. This reported interventional study was conducted in the Department of Sports - Exercise Medicine and Sciences, North-East Regional Centre (NERC), Sports Authority of India (SAI), Imphal. 
Effects of addition of sprint, strength and agility training on cardiovascular system in young male...

2.1Subjects: Thirty young male national level field hockey trainees of NERC, SAI, Imphal, (age: $15.7 \pm 1.55$ years, range: $13-20$ years; height $165.21 \pm 6.24 \mathrm{~cm}$ ) undergoing training in the preparation phase voluntarily participated in the study. A well informed and written consent was taken with detailed explanation of the study, including all possible complications. The study was approved by the Ethical Committee of the Institute.

2.2Procedures: The participants were already undergoing field hockey training consisting of aerobic, anaerobic and skill components for 2 hours per day and 6 times a week as their regular schedule. For our study, we incorporated a specialized training schedule as an additional 2 hours per day, 3 times a week of exercises consisting of sprint, strength-power and agility for a total of 6 weeks duration. The training consisted of 2 sessions of 11-22 yards straight sprints per day; free weights and machine based 8-10 isotonic resistance exercises affecting major muscle groups of the body at an intensity of 70-90\% of one repetition maximum and volume of 1-3 sets, 6-12 repetitions per day as strength-power training; and 2 sessions of 30-yard T-drills \& ZigZag drills as agility training. Players were given rest of not more than 3 minutes between each session of exercises. Echocardiographic parameters were measured at the beginning and after the end of 6 weeks of this training programme. All the tests were done in the morning about the same time ( \pm 1 hours) around a temperature range of $25 \pm 2^{\circ} \mathrm{C}$, with relative humidity of $60-65 \%$.

The anthropometric variables measured were standing height ( $\mathrm{HT}$ in $\mathrm{cm}$ ), body weight (BW in $\mathrm{kg}$ ), body mass index (BMI in $\mathrm{kg} / \mathrm{m}^{2}$ ) and lean body mass (LBM in $\mathrm{kg}$ ). For cardiovascular assessment, resting heart rate (rHR in bpm), resting systolic blood pressure (rSBP in $\mathrm{mmHg}$ ), resting diastolic blood pressure (rDBP in $\mathrm{mmHg}$ ) and resting double product or rate pressure product ( $\mathrm{rDP}$ in $\mathrm{mmHg} / \mathrm{min})$; echocardiography: resting left ventricular end-diastolic diameter $(\mathrm{rEDD}$ in $\mathrm{cm})$, resting left ventricular end-diastolic volume ( $\mathrm{rEDV}$ in $\mathrm{ml})$, resting left ventricular end-systolic diameter $(\mathrm{rESD}$ in $\mathrm{cm})$, resting left ventricular end-systolic volume (rESV in $\mathrm{ml})$, resting left ventricular posterior wall thickness ( $\mathrm{rPWT}$ in $\mathrm{cm}$ ), resting left ventricular ejection fraction (rEF in \%) and resting cardiac contractility index ( $\mathrm{rCI}$ in $\mathrm{mmHg} / \mathrm{ml}$ ) were measured. A Stadiometer (Seca220, UK) was used to measure the standing heights of all the subjects to nearest $0.1 \mathrm{~cm}$. Weight and body composition variables were measured using TANITA Body Composition Analyzer (TBF310 Model, Japan). Resting heart rates were measured by counting carotid pulse manually for one minute. A sphygmomanometer was used to measure resting blood pressures. Two dimensional echocardiographic evaluations were performed with Philips echocardiograph.

2.3Statistical analysis: SPSS (Statistical Package for Social Science) version 19 software was used for data analysis. Standard descriptive statistics were determined. Paired t-test was used to assess the changes in measured variables resulting from effects of training. Statistical significance was chosen at 0.05 levels.

\section{Results}

Table I shows mean and standard deviations of all measured parameters before and after the 6 weeks training, along with significance ( $\mathrm{p}$ value) of paired t test applied for comparison. Changes in measured parameters relative to change in LBMs are shown in table II.

Table I. Measured parameters before and after the 6 weeks specialized training in young male hockey players $(\mathbf{n}=\mathbf{3 0})$.

\begin{tabular}{|c|c|c|c|c|}
\hline \multirow{2}{*}{\multicolumn{2}{|c|}{ Parameters }} & Before & After & \multirow{2}{*}{$\begin{array}{c}\text { p-value } \\
\text { (paired t test) }\end{array}$} \\
\hline & & $($ Mean \pm SD) & $($ Mean \pm SD) & \\
\hline 1. & BW (kg) & $56.696 \pm 6.126$ & $56.589 \pm 6.096$ & 0.186 \\
\hline 2. & LBM $(\mathrm{kg})^{*}$ & $45.463 \pm 3.979$ & $45.663 \pm 3.933$ & 0.001 \\
\hline 3. & BMI $\left(\mathrm{kg} / \mathrm{m}^{2}\right)$ & $20.715 \pm 1.365$ & $20.649 \pm 1.392$ & 0.118 \\
\hline 4. & $\mathrm{rHR}(\mathrm{bpm}) *$ & $70.07 \pm 3.823$ & $68.80 \pm 4.737$ & 0.012 \\
\hline 5. & $\mathrm{rSBP}(\mathrm{mmHg})^{*}$ & $109.13 \pm 5.912$ & $108.17 \pm 5.849$ & 0.027 \\
\hline 6. & $\mathrm{rDBP}(\mathrm{mmHg}) *$ & $69.27 \pm 5.212$ & $67.73 \pm 5.699$ & 0.001 \\
\hline 7. & $\mathrm{rDP}(\mathrm{mmHg} / \mathrm{min}) *$ & $7647.27 \pm 583.273$ & $7445.80 \pm 689.97$ & 0.013 \\
\hline 8. & $\mathrm{rEDD}(\mathrm{cm})$ & $4.297 \pm 0.194$ & $4.313 \pm 0.187$ & 0.057 \\
\hline 9. & rEDV (ml) & $105.007 \pm 7.081$ & $105.307 \pm 7.072$ & 0.343 \\
\hline 10. & rESD $(\mathrm{cm})$ & $2.808 \pm 0.166$ & $2.768 \pm 0.256$ & 0.145 \\
\hline 11. & $\mathrm{rESV}(\mathrm{ml})^{*}$ & $39.546 \pm 3.805$ & $39.199 \pm 4.087$ & 0.049 \\
\hline 12. & rPWT $(\mathrm{cm})^{*}$ & $0.787 \pm 0.073$ & $0.800 \pm 0.074$ & 0.043 \\
\hline 13. & $\operatorname{rEF}(\%)^{*}$ & $62.312 \pm 2.939$ & $62.759 \pm 3.152$ & 0.025 \\
\hline 14. & $\mathrm{rCI}(\mathrm{mmHg} / \mathrm{ml})$ & $2.782 \pm 0.287$ & $2.787 \pm 0.318$ & 0.791 \\
\hline
\end{tabular}

*Significant $(\mathrm{p}<0.05)$ 
Effects of addition of sprint, strength and agility training on cardiovascular system in young male...

Table II. Effect of 6 week specialized training on selected resting echocardiographic variables relative to lean body mass among young male hockey players $(n=30)$.

\begin{tabular}{|c|c|c|c|c|}
\hline & Parameters & $\begin{array}{c}\text { Before } \\
(\text { Mean } \pm \text { SD })\end{array}$ & $\begin{array}{c}\text { After } \\
(\mathrm{Mean} \pm \mathrm{SD})\end{array}$ & $\begin{array}{c}\mathrm{p} \text {-value } \\
\text { (paired t test) }\end{array}$ \\
\hline 1. & $\mathrm{rEDD} / \mathrm{LBM}(\mathrm{cm} / \mathrm{kg})$ & $0.09515 \pm 0.00871$ & $0.09508 \pm 0.00851$ & 0.758 \\
\hline 2. & $\mathrm{rEDV} / \mathrm{LBM}(\mathrm{ml} / \mathrm{kg})$ & $2.32743 \pm 0.26472$ & $2.32228 \pm 0.25217$ & 0.444 \\
\hline 3. & $\mathrm{rESD} / \mathrm{LBM}(\mathrm{cm} / \mathrm{kg})$ & $0.06215 \pm 0.00562$ & $0.06090 \pm 0.00594$ & 0.051 \\
\hline 4. & $\mathrm{rESV} / \mathrm{LBM}(\mathrm{ml} / \mathrm{kg})$ & $0.87678 \pm 0.11894$ & $0.86761 \pm 0.11978$ & 0.051 \\
\hline 5. & $\mathrm{rPWT} / \mathrm{LBM}(\mathrm{cm} / \mathrm{kg})$ & $0.01745 \pm 0.00237$ & $0.01768 \pm 0.0025$ & 0.122 \\
\hline 6. & $\mathrm{rEF} / \mathrm{LBM}(\% / \mathrm{kg})$ & $1.3806 \pm 0.13311$ & $1.38398 \pm 0.13336$ & 0.331 \\
\hline 7. & $\begin{array}{l}\mathrm{rCI} / \mathrm{LBM} \\
(\mathrm{mmHg} / \mathrm{ml} / \mathrm{kg})\end{array}$ & $0.06150 \pm .00706$ & $0.06136 \pm .00782$ & 0.720 \\
\hline
\end{tabular}

*Significant $(\mathrm{p}<0.05)$

\section{Discussion}

Although no significant changes were observed in case of body weights and body mass indices, significant increment was found in the lean body masses of the players (Table I).This observation can be explained by the short duration of the training and relative reduction in fat mass of the players. Resistance exercise [9] causes considerable EPOC (Excess Post exercise Oxygen Consumption) [10-12] which may be greater than that of aerobic exercise [13] and also increases lean body mass. This results in higher energy expenditure and BMR, which may be elevated throughout the day following a work out, thereby reducing fat mass. Field hockey is one of the sports which demand a lean body from the player. The combination of weight training with sprint and agility training brings more substantial gains in muscle size than the later alone [14]. This change in body composition may improve the strength-to-weight ratio and hence the athletic performance.

Resting heart rate and resting blood pressure reduced significantly after the training (Table I), for which one possible explanation may be increased parasympathetic activity in the heart and decreased sympathetic activity, or increase in the activity of both the autonomic branches $[15,16]$. Besides changes in the sympathoadrenal drive, the reduction in body fat may also result in decrease resting blood pressure due to strength training [5]. Alteration in sodium excretion may also play a substantial role related to this finding [17]. Training causes increase in eNOS (endothelium nitric oxide synthase) gene transcription, eNOS mRNA stability and eNOS protein translation, resulting in increased nitric oxide formation from its precursor L-arginine, which may be due to repetitive episodic increases in endothelial cells shear stress [18]. Training also results in a decreased sensitivity to the vasoconstrictor effects of norepinephrine, possibly due to an endothelium-dependent mechanism involving alpha 2-adrenergic receptors [19]. This results in arteriole smooth muscle relaxation and vasodilatation, leading to reduction of total peripheral resistance. Nitric oxide also regulates exercise-induced glucose uptake and skeletal muscle contractility[20]. The decrease in total peripheral resistance may also be due to less vascular occlusion during muscular contraction, resulting from resistance training induced increase in maximal strength and hence decrease in percentage of maximal voluntary contraction necessary to obtain a submaximal absolute force or workload [21].

The significant increase in left ventricular ejection fraction (Table I) might initially cause more stretching and hence activation of the body's baroreceptors (aortic arch and carotid sinuses), thereby inhibiting vasoconstrictor center of medulla and exciting the vagal parasympathetic center, finally resulting in lowering of total peripheral resistance and heart rate. The cardiac output might slightly decrease as well due to training. The net effect is the decrease in arterial pressure since it is the product of the cardiac output and the peripheral resistance. In the study, we observed decrease in blood pressure accompanied by increase in lean body mass as contrast to some of the earlier research findings of positive correlation between the systolic blood pressure and body mass [22].

Double product or rate-pressure product which is the product of heart rate and systolic blood pressure, is a good estimate of myocardial work or internal work done, and is proportional to myocardial oxygen consumption [23]. There was significant reduction in resting double product after the training, indicating the left ventricle is performing less work and hence has lower oxygen consumption at rest. Besides training induced decrease in heart rate and systolic blood pressure, the reduction in DP may be due in part to training induced reduction in total peripheral resistance, and hence reduced afterload [5, 6, 21]. Reduction in myocardial wall tension is another reason which results due to resistance training induced significant increase in left ventricular posterior wall thickness with non significant changes in left ventricular chamber size: end-diastolic and endsystolic diameters (Table I). This is in accordance with Laplace's law, represented by the formula $\mathrm{T}=\mathrm{P} \times \mathrm{R} / \mathrm{Wt}$, where $\mathrm{T}$ is myocardial wall tension, $\mathrm{P}$ is transmural pressure, $\mathrm{R}$ is chamber radius or diameter/2 and $\mathrm{Wt}$ is wall thickness.

Among the changes in echocardiographic parameters (Table I), increments of left ventricular enddiastolic diameters and volumes were non-significant. There was significant decrease in left ventricular endsystolic volumes, though left ventricular end-systolic diameters didn't show significant decrease. The significant 
Effects of addition of sprint, strength and agility training on cardiovascular system in young male...

reduction in end-systolic volume with non significant change in end-diastolic volume indicated improvement in cardiac contractility [24] as a result of the training. The improvement in left ventricular systolic function is also indicated by the significant increase in left ventricular ejection fraction. The improvement of intrinsic contractile properties of cardiac muscles and increased response to inotropic stimulation may have resulted in an enhanced cardiac contractility, possibly due to increase sensitivity of cardiac myocytes to calcium when stretched.

The posterior wall thickness of left ventricles also increased significantly after the training, indicating increase in cardiac muscle mass. Upto $15 \%$ increase in estimated left ventricular mass can be due to a change of $1 \mathrm{~mm}$ in left ventricular thickness. The overloading and stretching of myocardium, due to exercise results in increased rate of protein synthesis, finally leads to hypertrophy. Pressure overload resulting from the intermittent rise in blood pressure and intrathoracic pressure occurring primarily during resistance training results in an increase in number of sarcomeres in parallel (concentric hypertrophy), whereas volume overload primarily due to aerobic training increases the number of sarcomeres in series (eccentric hypertrophy) [25].The echocardiographic findings indicated the adaptive cardiac hypertrophy more towards concentric side as a result of the additional 6 weeks, specialized training. It is to be noted that the increase in left ventricular thickness and mass was not associated with decrease in end-diastolic diameters or volumes (Table I), unlike in cases of pathological pressure overload conditions caused by hypertension or cardiac hypertrophy in various forms of cardiomyopathy [26]. Hence, diastolic function or the capacity for diastolic filling was not decreased, instead increased as indicated by the slight increment in end-diastolic diameters and volumes, as also reported earlier in elite athletes of other sports [27]. The increment in cardiac mass was also associated with decreased cardiac work load as there was significant reduction in rDP after the training (Table I), indicating a positive adaptation.

However, when the echocardiographic parameters were expressed relative to lean body mass, no significant changes were observed after the training (Table II). This suggested that the change in the parameters after the training might, at least in part, be brought about by the change in lean body mass. Moreover, the increased blood pressure and intrathoracic pressure during the resistance exercise which is attributed to concentric hypertrophy, is counterbalanced by the reduction in transmural pressure which is left ventricular pressure minus intrathoracic pressure. This may reduce the potential training effects on heart, independent of the body size changes [28-30].

Conclusion: the study proved that

- Only a 6 week short duration specialized additional training to the participants resulted in favorable physiological outcomes.

- Sprint, strength and agility training resulted in better body composition of the players by reducing body fat and increasing lean body mass.

- The training also resulted in significant morphological changes in heart.

- The training improved cardiovascular functional status in the participants favoring better performance in sports.

- The observed changes confirm favorable physiological adaptations and better health status as beneficial effect of exercise.

The above knowledge can be applied to design better training schedules for players and also for general population to improve their cardiovascular and overall health status. The study also provided information about physiology of sports and exercise related adaptations.

\section{Acknowledgements}

The authors would like to express their sincere gratitude to the Director Incharge, North-East Regional Centre, Sports Authority of India; and Incharge, Sports Sciences and Fitness Centre, NERC-SAI, for their valuable and administrative contribution. Authors also acknowledge valuable cooperation and contribution of the field hockey coaches, physiotherapy staff, nursing staff and hockey trainees who have participated in this study.

\section{References}

[1]. J. Bloomfield, R. Polman, P. O'Donoghue and L. McNaughton, Effective speed and agility conditioning methodology for random intermittent dynamic type sports, Journal of Strength \& Conditioning Research,21(4), 2007, 1093-1100.

[2]. M.T. Elferink-Gemser, C. Visscher, M.A. van Duijn and K.A. Lemmink, Development of the interval endurance capacity in elite and sub-elite youth field hockey players, British Journal of Sports Medicine,40(4), 2006, 340-345.

[3]. T. Hinrichs, J. Franke, S. Voss, W. Bloch, W. Schanzer and P. Platen, Total hemoglobin mass, iron status, and endurance capacity in elite field hockey players, Journal of Strength \&Conditioning Research,24(3),2010, 629-638.

[4]. G.A. Kelley and K.S. Kelley, Progressive resistance exercise and resting blood pressure : A meta-analysis of randomized controlled trials, Hypertension,35(3), 2000, 838-843.

[5]. A.P. Goldberg, Aerobic and resistive exercise modify risk factors for coronary heart disease, Medicine \& Sciencein Sports \&Exercise, 21(6),1989, 669-674. 
Effects of addition of sprint, strength and agility training on cardiovascular system in young male...

[6]. D.G. Sale, D.E. Moroz, R.S. McKelvie, J.D. MacDougall and N. McCartney, Comparison of blood pressure response to isokinetic and weight-lifting exercise, European Journal of Applied Physiology and Occupational Physiology,67(2),1993, 115-120.

[7]. B.J. Maron, Structural features of the athlete heart as defined by echocardiography, Journal of American College of Cardioliology, 7(1),1986, 190-203.

[8]. L.A. Wolfe, D.A. Cunningham and D.R. Boughner, Physical conditioning effects on cardiac dimensions: a review of echocardiographic studies, Canadian Journal of Applied Sport Sciences, 11(2),1986, 66-79.

[9]. C.A. Binzen, P.D. Swan and M.M. Manore, Postexercise oxygen consumption and substrate use after resistance exercise in women, Medicine \& Science in Sports \& Exercise,33(6),2001, 932-938.

[10]. E. Borsheim and R. Bahr, Effect of exercise intensity, duration and mode on post-exercise oxygen consumption, Sports Medicine,33(14), 2003, 1037-1060.

[11]. W.A. Braun, W.E. Hawthorne and M.M. Markofski, Acute EPOC response in women to circuit training and treadmill exercise of matched oxygen consumption, European Journal of Applied Physiology,94(5-6), 2005, 500-504

[12]. N.A. Ratamess, M.J. Falvo, G.T. Mangine, J.R. Hoffman, A.D. Faigenbaum and J. Kang, The effect of rest interval length on metabolic responses to the bench press exercise, European Journal of Applied Physiology, 100(1), 2007, 1-17.

[13]. M.A. Burleson, Jr., H.S. O'Bryant, M.H. Stone, M.A. Collins and T. Triplett-McBride, Effect of weight training exercise and treadmill exercise on post-exercise oxygen consumption, Medicine \& Science in Sports \& Exercise,30(4), 1998, 518-522.

[14]. J. Perez-Gomez, H. Olmedillas, S. Delgado-Guerra, I. Ara, G. Vicente-Rodriguez, R.A. Ortiz, et al., Effects of weight lifting training combined with plyometric exercises on physical fitness, body composition, and knee extension velocity during kicking in football, Applied Physiology Nutrrition and Metabolism,33(3), 2008, 501-510.

[15]. R.L. Goldsmith, J.T. Bigger, Jr., R.C. Steinman and J.L. Fleiss, Comparison of 24-hour parasympathetic activity in endurancetrained and untrained young men, Journal of American College of Cardioliology,20(3), 1992, 552-558.

[16]. R. Gonzalez-Camarena, S. Carrasco-Sosa, R. Roman-Ramos, M.J. Gaitan-Gonzalez, V. Medina-Banuelos and J. Azpiroz-Leehan, Effect of static and dynamic exercise on heart rate and blood pressure variabilities, Medicine \& Science in Sports \& Exercise,32(10), 2000, 1719-1728.

[17]. L.S. Pescatello, B.A. Franklin, R. Fagard, W.B. Farquhar, G.A. Kelley and C.A. Ray, American College of Sports Medicine position stand. Exercise and hypertension, Medicine \& Science in Sports \& Exercise, 36(3), 2004, 533-553.

[18]. R.M. McAllister and M.H. Laughlin, Vascular nitric oxide: effects of physical activity, importance for health, Essays in Biochemistry, 42, 2006, 119-131.

[19]. M.D. Delp, Effects of exercise training on endothelium-dependent peripheral vascular responsiveness, Medicine \& Science in Sports \&Exercise, 27 (8), 1995, 1152-1157.

[20]. D.S. Bredt, Endogenous nitric oxide synthesis: biological functions and pathophysiology, Free Radical Research,31 (6), 1999,577 596.

[21]. E.J. Marcinik, J. Potts, G. Schlabach, S. Will, P. Dawson and B.F. Hurley, Effects of strength training on lactate threshold and endurance performance, Medicine \& Science in Sports \&Exercise, 23 (6), 1991, 739-743.

[22]. J.T. Viitasalo, P.V. Komi and M.J. Karvonen, Muscle strength and body composition as determinants of blood pressure in young men, European Journal of Applied Physiology and Occupational Physiology,42(3), 1979, 165-173.

[23]. F.L. Gobel, L.A. Norstrom, R.R. Nelson, C.R. Jorgensen and Y. Wang, The rate-pressure product as an index of myocardial oxygen consumption during exercise in patients with angina pectoris, Circulation,57(3), 1978, 549-556.

[24]. M. Jensen-Urstad, F. Bouvier, M. Nejat, B. Saltin and L.A. Brodin, Left ventricular function in endurance runners during exercise, Acta Physiologica Scandinavica,164(2), 1998, 167-172.

[25]. M.B. Effron, Effects of resistive training on left ventricular function, Medicine \& Science in Sports \&Exercise, 21(6), 1989, 694697.

[26]. A. Urhausen and W. Kindermann, Echocardiographic findings in strength- and endurance-trained athletes, Sports Medicine, 13(4), 1992, 270-284

[27]. S.D. Colan, S.P. Sanders, D. MacPherson and K.M. Borow, Left ventricular diastolic function in elite athletes with physiologic cardiac hypertrophy, Journal of American College of Cardiology,6(3), 1985, 545-549.

[28]. M.J. Haykowsky, R. Dressendorfer, D. Taylor, S. Mandic and D. Humen, Resistance training and cardiac hypertrophy: unravelling the training effect, Sports Medicine,32(13), 2002, 837-849.

[29]. S.J. Fleck, Cardiovascular adaptations to resistance training, Medicine \& Science in Sports \&Exercise, 20(5 suppl), 1988, S146-151.

[30]. M. Haykowsky, D. Taylor, K. Teo, A. Quinney and D. Humen, Left ventricular wall stress during leg-press exercise performed with a brief Valsalva maneuver, Chest,119(1),2001, 150-154. 